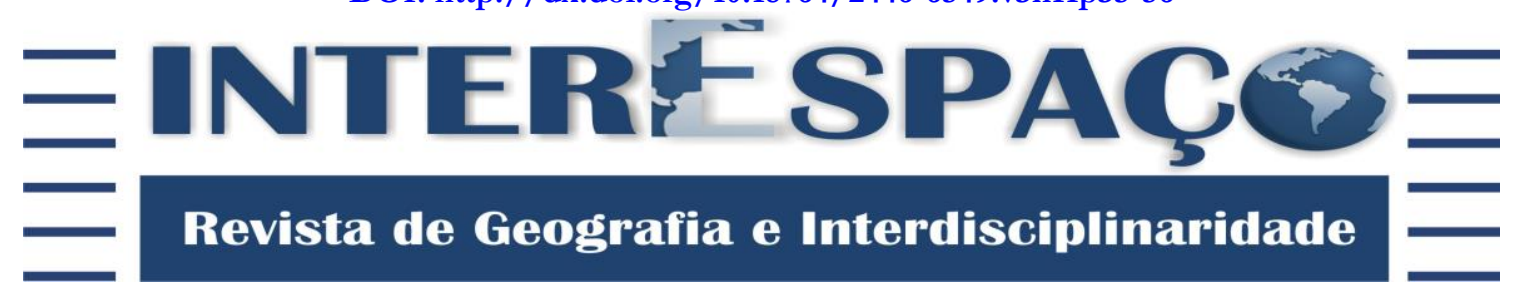

\title{
O CINEMA COMO FONTE INVESTIGATIVA PARA COMPREENSÃO DA INFÂNCIA: o uso de recursos audiovisuais no ensino de psicologia
}

\section{THE CINEMA AS AN INVESTIGATIVE SOURCE FOR UND ERSTANDING CHILDREN: the use of audiovisual resources in teaching psychology}

EL CINE COMO FUENTE INVESTIGADORA PARA LA COMPRENSÍON DE LA INFÂNCIA: el uso de recursos audiovisuales en la enseñanza de psicología

\section{Laura Maria Silva Araújo Alves}

Psicóloga. Doutora em Educação (Psicologia da Educação) pela Pontifícia Universidade Católica de São Paulo - PUC/SP. Professora do Instituto de Ciências da Educação e do Programa de Pósgraduação em Educação da Universidade Federal do Pará - UFPA. Pesquisadora da História da Infância na Amazônia. laura_alves@uol.com.br

Recebido para avaliação em 03/02/2017; Aceito para publicação em 31/10/2017.

\section{RESUMO}

O presente artigo apresenta a utilização de recurso audiovisual como componente didático nas aulas de Psicologia em uma instituição pública de ensino superior. A contribuição dessa prática resulta da experiência levada a cabo durante vários anos de docência no ensino de Psicologia para os Cursos de Licenciaturas na aplicabilidade didática de filmes numa perspectiva de que as produções cinematográficas possam contribuir para as discussões sobre a compreensão da infância. Considerando que o cinema detém a expressão da realidade, por o que está na tela parecer reproduzir as características do mundo, sobretudo o que se vê no cotidiano, os filmes são ferramentas de auxílio para a compreensão de diversos conceitos sobre infância, pois não só informam, mas são capazes de instrumentalizar o aluno sobre o universo da criança. Portanto, pretendemos então destacar por meio da narrativa cinematográfica a compreensão da criança e os desdobramentos com as teorias psicológicas clássicas sobre o desenvolvimento e aprendizagem infantil. Para análise trazemos documentários e filmes que tem como protagonista a criança e ambientada em diversos contextos socioculturais. Constatamos que o uso de filmes nas aulas de psicologia proporcionou a interação entre o conteúdo das teorias da aprendizagem e desenvolvimento com o universo da criança, ou seja, a articulação da teoria com a prática.

Palavras-chave: Psicologia; Cinema; Infância; Teorias Psicológicas.

\section{ABSTRACT}

This article presents the use of audio-visual resource as a didactic component in Psychology classes in a public institution of higher education. The contribution of this practice results from the experience carried out during several years of teaching in Psychology for the degree programs in the didactic applicability of films with a view that the cinematographic productions can contribute to the discussions about the understanding of childhood. Considering that cinema holds the expression of reality, because what is on the screen seems to reproduce the characteristics of the world, especially what is seen in everyday routines, movies are implement to help understand various concepts about childhood, because they do not only inform, but are able to instrumentalize the student about the universe of the child. Therefore, we intend to then through the cinematographic narrative the understanding of the child and the unfolding with the classic 
Dossiê: Diálogos interdisciplinares em Psicologia da Educação

| O cinema como fonte investigativa para compreensão da infância: o uso de recursos audiovisuais no ensino de psicologia|

\section{| Laura Maria Silva Araújo Alves |}

psychological theories about development and learning infant. For analysis we bring documentaries and films that have as protagonist the child and acclimated in diverse sociocultural contexts. We found that the use of films in psychology classes provided the interaction between the content of learning and development theories with the universe of the child, that is, the articulation of theory with practice.

Keywords: Psychology; Movie Theatre; Childhood; Psychological Theories.

\section{RESUMEN}

El presente artículo presenta el uso de recurso audiovisual como componente didáctico en clases de psicología en una institución universitaria pública. La contribución de esa práctica resulta de la experiencia llevada a cabo durante varios años de docencia en la de psicología para los cursos de licenciaturas en la aplicación didáctica de películas en una perspectiva de que las producciones cinematográficas puedan contribuir para las discusiones sobre la comprensión de la infancia. Considerando que el cine detiene la expresión de la realidad, porque lo que está en la pantalla parece reproducir las características del mundo, sobre todo lo que se ve en lo cotidiano, las películas son herramientas de auxilio para la comprensión de diversos conceptos sobre la infancia, pues no solo informan, sino que también son capaces instrumentalizar el alumno sobre el universo de los niños. Por lo tanto, pretendemos entonces destacar por medio de narrativa cinematográfica la comprensión de los niños y los desdoblamientos con las teorías psicológicas clásicas sobre el desarrollo y aprendizaje infantil. Para el análisis traemos documentales y películas que tienen como protagonista a los niños y ambientado en diversos contextos socioculturales. Constatamos que el uso de películas en la clases de psicología proporcionó la interacción entre el contenido de las teorías de aprendizaje y desarrollo con el universo de los niños, o sea, la articulación de la teoría con la práctica.

Palabras clave: Psicología; Cine; Infancia; Teorías Psicológicas.

\section{INTRODUÇÃO}

"O Cinema é como um sonho, como uma música. Nenhuma arte perpassa a nossa consciência da forma como o filme faz; vai diretamente até nossos sentimentos, atingindo a profundidade dos quartos escuros de nossa alma” (IGMAR BERGMAM).

O ensino e os conteúdos das disciplinas de Psicologia ${ }^{1}$ nos cursos de graduação, especialmente os cursos de Licenciaturas, apresentam especificidades que geram a necessidade de refletir sobre sua prática. Um dos aspectos recorrentemente destacados pelos alunos das licenciaturas é, de um lado, o caráter teórico dessa disciplina e, de outro lado, o distanciamento dos conteúdos psicológicos com a prática docente ${ }^{2}$. Para solucionar este déficit, o ensino de Psicologia tem passado por profundas mudanças nos últimos anos, principalmente no sentido de possibilitar ao futuro professor sua instrumentalização para

\footnotetext{
1 Neste estudo estamos nos referindo às disciplinas tradicionalmente denominadas "Psicologia da Aprendizagem" e "Psicologia do Desenvolvimento". Estas são geralmente ministradas nos cursos de licenciaturas. No caso da UFPA, o curso de licenciatura em Letras teve reformulação curricular que desencadeou uma única disciplina denominada Psicologia da Aprendizagem.

${ }^{2}$ Com relação entre teoria e prática, a ênfase dada nos cursos de graduação foi de superar essa dicotomia. Consideramos que a Psicologia nos cursos de formação de professores constitui-se em uma das disciplinas que deveria fundamentar a formação dos professores, especialmente no que se refere aos processos de constituição do ser humano e os processos ensino-aprendizagem.
} 
Dossiê: Diálogos interdisciplinares em Psicologia da Educação

| O cinema como fonte investigativa para compreensão da infância: o uso de recursos audiovisuais no ensino de psicologia|

| Laura Maria Silva Araújo Alves |

posterior intervenção na realidade. Dessa forma, a articulação entre teoria e a prática mostra a necessidade de preparar melhor os alunos para enfrentar o cotidiano da sala de aula e a especificidades da criança.

As utilizações de novas tecnologias como suporte para o desenvolvimento do ensino têm sido recorrentemente utilizadas como uma ferramenta para o atrelamento da teoria com a prática. Entre os vários recursos utilizados na educação, inclui-se o cinema como um instrumento pedagógico interessante nas aulas de Psicologia ${ }^{3}$. A contribuição dessa prática resulta da experiência levada a cabo durante vários anos de docência no ensino de Psicologia para os Cursos de Licenciaturas na aplicabilidade de filmes, numa perspectiva de que as produções cinematográficas possam contribuir para as discussões sobre a compreensão da infância e suas interfaces psicológicas. Considerando que o cinema detém a expressão da realidade e reproduz práticas culturais e educação, os filmes são ferramentas de auxílio para a compreensão de diversos temas sobre a infância, pois não só informam, mas são capazes de instrumentalizar o aluno de graduação na perspectiva biopsicossocial da criança. Enfim, a linguagem cinematográfica é um instrumento para demonstrar as temáticas que circundam o universo infantil.

O presente artigo apresenta a utilização do cinema como recurso audiovisual e componente didático nas aulas de Psicologia. A experiência do uso de filmes e documentários no ensino de Psicologia aconteceu em duas turmas de Graduação em Letras na Universidade Federal do Pará, nos anos de 2013 a 2014. De acordo com o Projeto Político Pedagógico do curso de Licenciatura em Letras, a disciplina de Psicologia abrange as principais Teorias Clássicas da Aprendizagem (Skinner, Piaget, Wallon e Vygotsky) ${ }^{4}$. Seus conteúdos objetivam instrumentalizar os alunos sobre os conhecimentos psicológicos da infância e os processos culturais e educativos escolares e não escolares. Após a apresentação de cada abordagem teórica da Psicologia realizamos sessões de filmes na intenção de fazer o aluno de graduação discutir os conteúdos apreendidos nas aulas expositivas. Após as sessões de filmes, foi solicitado que cada aluno elaborasse um texto no qual abordasse uma análise dos elementos presentes no filme com os conteúdos das teorias psicológicas.

\footnotetext{
3 Ao longo da nossa experiência na docência ministrando conteúdos de Psicologia para os cursos de licenciaturas observamos que os alunos vão se envolvendo com os conteúdos da disciplina quando da realização de atividades em que é possível aplicar a teoria no contexto prático. O distanciamento entre e teoria e a prática pode ser minimizado com estratégias didáticas como, por exemplo, estudo de caso, com o objetivo de instrumentalizar o aluno a vivenciar de situações em que ele terá que estabelecer intervenções no contexto pedagógico.

${ }^{4} \mathrm{Na}$ mais recente grade curricular do curso de Letras da UFPA, a Psicologia da Educação foi substituída pela disciplina Psicologia da Aprendizagem na qual são trabalhados conteúdos referentes às teorias clássicas da aprendizagem e suas implicações no ensino.
} 
Dossiê: Diálogos interdisciplinares em Psicologia da Educação

| O cinema como fonte investigativa para compreensão da infância: o uso de recursos audiovisuais no ensino de psicologia|

| Laura Maria Silva Araújo Alves |

Para elaboração das sessões de filmes escolhemos cinco produções cinematográficas sobre a infância, sendo dois documentários e três filmes. Para escolha dos filmes e documentários privilegiamos aqueles que apresentavam:

(1) a criança como protagonista da narrativa;

(2) temas relacionados ao universo infantil com práticas culturais e educação;

(3) elementos contextuais como cultura, sociedade e educação;

(4) aspectos da infância relacionados às teorias psicológicas.

Tendo então o uso de filmes no ensino da Psicologia no curso de Graduação em Letras, os objetivos foram: (1) Destacar a relevância da utilização de filmes como recursos didáticos para discussões sobre a infância na disciplina de Psicologia; (2) Identifica os filmes que podem ser utilizados nas aulas de Psicologia que retratam a infância; (3) Abordar como os filmes podem desenvolver nos alunos a compreensão da infância; (4) Analisar que elementos da infância são abordados nos filmes que podem ser relacionados com os conteúdos sobre infância e as teorias psicológicas do desenvolvimento e aprendizagem.

O presente artigo está dividido em três momentos: (1) o ensino da psicologia e desenvolvimento nos cursos de graduação; (2) o cinema como recurso áudio visual no contexto do ensino da Psicologia e (3) a infância no cinema e o ensino da psicologia da aprendizagem e desenvolvimento.

\section{O ENSINO DA PSICOLOGIA DA APRENDIZAGEM E DESENVOLVIMENTO NOS CURSOS DE GRADUAÇÃO}

Sabe-se que a Psicologia ao longo de sua história esteve sempre relacionada com o processo de atuação docente, sobretudo na preparação de professores para o exercício profissional. Como área de conhecimento pedagógico, cujas teorizações procuram fornecer subsídios para as práticas educativas, a Psicologia chega até os cursos de formação docente com um propósito: a de promover embasamento teórico dos processos de desenvolvimento e aprendizagem (GATTI, 1995).

A Psicologia é hoje uma disciplina que está presente em vários currículos de cursos de graduação, pois o conhecimento psicológico é um saber importante para os profissionais que atuam na educação, principalmente para aqueles que estão em cursos de formação de professores e que vão atuar como docentes. A Psicologia da Aprendizagem se constitui em um conhecimento que subsidia o professor acerca do comportamento do aprendiz e dos processos de aprendizagem, para que, ao deparar-se com situações do 
Dossiê: Diálogos interdisciplinares em Psicologia da Educação

| O cinema como fonte investigativa para compreensão da infância: o uso de recursos audiovisuais no ensino de psicologia|

| Laura Maria Silva Araújo Alves |

cotidiano escolar que demandem ações pedagógicas possam usá-los adequadamente no processo ensino-aprendizagem (GATTI, 1997).

A Psicologia pode contribuir para a inserção do professor na realidade escolar, ajudando-o a rever a teoria e perceber as possibilidades de intervenção na prática. Neste sentido, a Psicologia passa a se configurar nos currículos de formação de professores como uma disciplina pedagógica e que precisa estar atrelada à realidade concreta.

\begin{abstract}
Esta posição requer um trânsito contínuo da análise das questões cotidianas presentes nas salas de aula e nas escolas para os fins e funções da Educação na sociedade (cidadania, sobretudo). Daí a necessidade da pesquisa no espaço escolar e da constante problematização de temas e tarefas emergentes dessa realidade. A condução do ensino de Psicologia através de problematizações temáticas, potencialmente, sugere um desenvolvimento profissional mais crítico e reflexivo, porque, ao fundamentar-se na pesquisa sobre a prática, aprende-se a reconhecê-la, a refletir sobre ela com a ajuda dos instrumentais teóricos da Psicologia e do mirante de questionamento sobre a relação educação-sociedade para, finalmente, erigir teorizações próprias que constituirão a base da intervenção no real (LAROCCA, 2000, p. 64).
\end{abstract}

O ensino da Psicologia nos cursos de formação tem sido objeto de estudo de Gatti, Batista, Azzi e Sadalla (2000) em diferentes contextos e perspectivas. As autoras ressaltam que o ensino da Psicologia nos cursos de formação docente caracteriza-se pela aplicação dos conhecimentos sobre os processos de desenvolvimento e aprendizagem na disciplina intitulada Psicologia da Educação. Em geral, os conhecimentos psicológicos são estruturados no núcleo de Fundamentos da Educação de forma fragmentada em duas disciplinas presentes nos currículos: Psicologia do Desenvolvimento e Psicologia da Aprendizagem. Além disso, há problemas de carga horária insuficiente e descontextualizada da realidade social e educativa.

A Psicologia é uma área que traz contribuição à prática educativa e pode proporcionar elementos para a melhoria da educação. Entretanto, concordamos com Gatti (1995) e Larocca (2007a) de que ensino da psicologia nos cursos de licenciaturas apresenta uma mentalidade herdada do Positivismo que contribuiu para uma compreensão de que primeiro a teoria e depois a prática.

O ensino de Psicologia na formação dos professores por muito tempo traduziu este modelo com a concepção de Psicologia Aplicada à Educação. Nesta concepção entendia-se que cabia à pesquisa em Psicologia gerar os conhecimentos científicos que se aplicariam de modo racional à resolução de problemas do âmbito educacional. De maneira semelhante, as licenciaturas, fortemente influenciadas pela racionalidade técnica, adotavam tradicionalmente uma organização curricular sequencial do tipo "teoria antes", "prática depois", supondo que as disciplinas básicas ou teóricas tinham a função de compreender, interpretar e prescrever os modos de aproximação e de resolução de problemas 
Dossiê: Diálogos interdisciplinares em Psicologia da Educação

| O cinema como fonte investigativa para compreensão da infância: o uso de recursos audiovisuais no ensino de psicologia|

| Laura Maria Silva Araújo Alves |

só encontrados e discutidos pelas disciplinas "práticas", cuja função era apresentar aos licenciados o campo educacional propriamente dito (LAROCCA, 2007, p. 300-301).

A Psicologia tem um papel que se traduz tanto pelas possibilidades para o desenvolvimento dos conteúdos psicológicos quanto pelas limitações em explicar a realidade escolar. Isto é,

possibilidades, como fonte de conhecimento sobre os processos de aprendizagem e desenvolvimento humano; limitações, na medida em que a complexidade pedagógica só pode ser entendida se considerarmos a teia de relação entre os seus diferentes e contraditórios aspectos, o que significa que a psicologia não pode sozinha explicar a realidade escolar (AZZI; BATISTA; SADALLA, 2000, p. 105).

É importante assinalar ainda que Psicologia instrumentaliza o graduando de licenciatura a lidar com os fenômenos educativos para melhor desenvolvimento da aprendizagem na sua atuação docente, pois

\begin{abstract}
a Psicologia pode contribuir para que o futuro professor ultrapasse o nível do senso comum, à medida que os conhecimentos teóricos vão favorecendo a compreensão do fenômeno da educação em diferentes dimensões, como a psicológica social, a antropologia, a biologia, a política etc. As contribuições dos fundamentos psicológicos da educação, em combinação com todos os outros fundamentos teóricos, podem facilitar o estabelecimento de melhor relação professor-aluno e melhor atuação docente (AZZI; BATISTA; SADALLA, 2000, p. 105).
\end{abstract}

A Psicologia é constituída por um corpo de conhecimento formado através da investigação psicológica promovendo a compreensão do sujeito sob ação educativa ${ }^{5}$. É por meio dos conteúdos psicológicos, principalmente pelas teorias da Aprendizagem e Desenvolvimento que entendemos o universo dos sujeitos na infância (GOULART, 1983).

Os estudos realizados com alunos egressos dos cursos de licenciatura da Unicamp sobre a contribuição da Psicologia (Educacional, Desenvolvimento e Aprendizagem) nas práticas pedagógicas apontam que os alunos classificaram a formação que tiveram como "razoavelmente adequada ou pouco adequada". Os resultados indicam ainda que seja

\footnotetext{
${ }^{5}$ Segundo Gatti (1996, pp.85-86), “os professores, como seres sociais concretos, com um modo próprio de estar no mundo, de ver as coisas, de interpretar informações, são ignorados pelas pesquisas e pelas políticas de intervenção que lidam de forma objetal ou abstrata com esses profissionais". Para a referida autora, "esse profissional é um ser em movimento, construindo valores, estruturando crenças, tendo atitudes, agindo em razão de um tipo de eixo pessoal que o distingue de outros: sua identidade. Associada à identidade estão as motivações, os interesses, as expectativas, as atitudes, todos elementos multideterminantes dos modos de ser profissionais".
} 
Dossiê: Diálogos interdisciplinares em Psicologia da Educação

| O cinema como fonte investigativa para compreensão da infância: o uso de recursos audiovisuais no ensino de psicologia|

| Laura Maria Silva Araújo Alves |

preciso redimensionar as disciplinas de Psicologia, sobretudo articulando teoria com a prática (MERCURI; SOARES; BATISTA, 1999).

Ao discutir o ensino de Psicologia nos cursos de formação de professores, Gatti (2000) sinaliza para o distanciamento do ensino da Psicologia da realidade escolar, consolidando não somente a dicotomia teoria e prática, mas desenhando um ensino ancorado num discurso sobre a prática docente à necessária interlocução com professores e alunos em seus ambientes concretos de construção do processo pedagógico.

As teorias psicológicas orientaram as práticas educativas dos futuros professores. Diante de uma pluralidade teórica a ser aplicada à Educação, a Psicologia, enquanto disciplina pedagógica, pôde orientar processos de desenvolvimento e aprendizagem e dar importantes contribuições para o ensino e a aprendizagem escolar (OLIVEIRA, 1993).

O papel da Psicologia é o de oferecer subsídios para a formação do professor no sentido de contribuir na articulação entre teoria e prática e conteúdo-forma, oferecendo, sobretudo elementos de análise para a prática pedagógica. Segundo Larocca (2007), o desenvolvimento da capacidade reflexiva é uma condição necessária e importante para que o profissional construa suas próprias teorias acerca da ação que pratica do campo em que atua e dos fins que persegue com a sua atividade docente. Diz a autora:

\footnotetext{
Impõe-se, portanto, fazer avançar a formação na perspectiva de desenvolver, nos estudantes que serão professores, um pensamento social e político mais comprometido com a emancipação da condição humana e mais capaz de empreender rupturas nas concepções ingênuas e nas práticas educativas tradicionais. Posicionamos, pois, a necessidade de contrapor à perspectiva técnica uma perspectiva reflexiva, crítica e emancipatória, que conceba o papel do professor, não como técnico, nem simplesmente um prático, mas o de um intelectual transformador da realidade em que vive (LAROCCA, 2007, p. 61).
}

Em geral, a dicotomia entre teoria e prática no ensino da psicologia nos cursos de Licenciaturas é superada com atividades de observação, pesquisas de campo e estudos de caso entre outras atividades, pois somente através da imersão dos alunos no mundo real é que se estará permitindo efetivamente ato de conhecimento, pois as práticas pedagógicas que não problematizam o real certamente não formarão profissionais reflexivos, criativos, críticos, autônomos e investigador constante de sua prática (GOULART, 1983). A articulação teoria e prática no âmbito da Psicologia deve ser uma constante, pois como ressalta Larocca (2000, p. 64), “a condução do ensino de psicologia através de problematização temáticas, potencialmente, sugere um desenvolvimento profissional mais crítico e reflexivo". 
Dossiê: Diálogos interdisciplinares em Psicologia da Educação

| O cinema como fonte investigativa para compreensão da infância: o uso de recursos audiovisuais no ensino de psicologia|

\section{| Laura Maria Silva Araújo Alves |}

A melhor maneira de atrelar teoria e prática é um ensino contextualizado que deve ser baseado em problemas e estratégias que levem os alunos a se defrontarem com situação real ou simulada através da pesquisa e de outras ferramentas tecnológicas como, por exemplo, o uso de filmes, documentários e curtas para articular aspectos das teorias com a prática. Para minimizar o distanciamento da teoria com a prática, introduzimos no ensino de Psicologia sessões de filmes com o objetivo de promover no aluno (futuro professor) desenvolvimento dos conteúdos e de assimilação às teorias da Aprendizagem e do desenvolvimento na infância. Portanto, os filmes se constituem como ferramenta didática para construir nos alunos das licenciaturas conhecimentos sobre a criança e suas infâncias.

\section{O CINEMA COMO RECURSO ÁUDIO-VISUAL NO CONTEXTO DO ENSINO DE PSICOLOGIA}

No final do Século XIX nasce aquela que será chamada a sétima arte - o cinema. A força do cinema consiste na sua relação com a realidade e com a capacidade que tem de fixar o tempo através das suas manifestações factuais. O cinema é um espaço de produção simbólica e de representação da realidade. Como manifestação polissêmica discursiva, o cinema indubitavelmente fornece elementos que nos ajudam a compreender aspectos da realidade concreta.

O cinema, considerado a sétima arte, representa um gênero artístico próprio. $O$ registro cinematográfico pode ser considerado um medidor social, pois a vivacidade das imagens e sua reprodutividade facilitam sua aceitação como representação da realidade. $O$ fato de o cinema reproduzir a complexidade da vida cotidiana e dos dilemas humanos the confere a possibilidade de contribuir para construção, reconstrução e sedimentação de conhecimentos, atitudes e valores do mundo social e cultural.

É como os filmes e documentários que surge a verdadeira técnica narrativa cinematográfica. Entretanto, o conceito de narrativa não pode ser pensado num contexto único ou estritamente literário. Narrar, contar uma seqüência de acontecimentos que se desenrolam num determinado "espaço" e "tempo" é o grande desafio do cinema. Sem a narrativa, o cinema vira algo insignificante, por isso toda a sua elaboração é baseada em narração. Assim, a capacidade cinematográfica ganha vida quando se impõe a ela um funcionamento narrativo capaz de justificar a imagem e a envolver o telespectador. $\mathrm{O}$ Cinema - nos anos 20, 30 e 40 do século passado - já tinha se tornado um objeto de estudo para aqueles que queriam investigar "não apenas os textos e contextos, mas sobre os 
Dossiê: Diálogos interdisciplinares em Psicologia da Educação

| O cinema como fonte investigativa para compreensão da infância: o uso de recursos audiovisuais no ensino de psicologia|

\section{| Laura Maria Silva Araújo Alves |}

processos históricos principalmente no desvendamento da alma humana e dos mundos que o homem foi capaz de criar para suas vidas, com suas relações sociais" (NÓVOA; FRESSATO; FEIGELSON, 2009, p. 169).

Sobre a utilidade dos estudos sobre fenômenos históricos e humanos a partir das fontes cinematográficas ${ }^{6}$, o cinema passa a ser para os sociólogos, historiadores, psicólogos e pesquisadores das áreas das ciências humanas um modelador de mentalidades, sentimentos e emoções de sujeitos históricos. Enfim, "o cinema é um difusor de ideias e sobre a história de modo mais ou menos pedagógico" (NÓVOA; FRESSATO; FEIGELSON, 2009, p. 175).

Os filmes que abordam a infância revelam processos figurativos, narrativos e lineares do universo da criança. Uma grande parte dos filmes prioriza a ficção, embora entendemos que a realidade se expressa em uma linguagem ficcional, pois o roteirista se baseia em fatos reais para construção das personagens e dos fatos narrados. Contudo, acreditamos que existe um compromisso dos filmes em abordar a infância de uma forma mais real possível.

A criança retratada pela produção cinematográfica, ao longo do tempo, passou do papel de simples sujeito em um contexto narrativo para abordagens concretas sobre o universo da infância. Nesta perspectiva, a designação de "filme sobre a infância" parece ter um público realmente interessante em entender aspectos que circundam à criança. Em geral, as personagens infantis presentes nas produções cinematográficas dizem respeito às crianças cujas idades vão de 6 a 11/12 anos. Ademais, os filmes retratam significativamente elementos no contexto sociocultural e de práticas educativas que representam o contexto da infância à luz da própria criança. Enfim, são filmes em que a criança é a protagonista da história. Há, portanto, a voz da criança expressando questões típicas da realidade infantil. Temas como abandono, trabalho infantil, violência, escola, família, pobreza, afetividade, castigos corporais, orfandade, disciplinamento, brincadeiras entre outros, são recorrentes nos filmes nacionais e estrangeiros.

A utilização de filmes como recurso pedagógico para reflexão sobre a infância deve ser acompanhada das várias abordagens teóricas da Psicologia da Aprendizagem e Desenvolvimento. A combinação de leitura dessas abordagens teóricas na psicologia e a sua aplicabilidade à discussão de filmes no espaço da sala de aula propiciam situações favoráveis ao entendimento do universo da criança e seus saberes sociais, culturais e

${ }^{6}$ Após um levantamento exaustivo sobre os filmes que retratam a infância procuramos escolher os que se adequavam às teorias psicológicas abordadas nas aulas. De posse dos filmes orientamos primeiramente os alunos a desenvolver um roteiro dos pontos mais significativos do filme e, posteriormente, uma relação e discussão desses pontos com as teorias. 
Dossiê: Diálogos interdisciplinares em Psicologia da Educação

| O cinema como fonte investigativa para compreensão da infância: o uso de recursos audiovisuais no ensino de psicologia|

\section{| Laura Maria Silva Araújo Alves |}

afetivos. No âmbito do ensino da Psicologia, o filme pode ser comparado a um "estudo de caso" cuja história apresenta um fio condutor que permite aproximação do aluno de graduação com a realidade concreta e a entender conflitos extremamente relacionados à infância.

A utilização de filmes como recurso pedagógico para reflexão sobre complexas questões éticas relacionadas à prática de pesquisa deve ser acompanhada de referencial analítico para subsidiar o debate. A combinação de leitura à discussão de filmes em sala de aula propicia situações favoráveis ao desenvolvimento de habilidades éticas que se traduzirão em práticas. O recurso audiovisual atua como elemento facilitador da dinâmica do processo de ensino-aprendizagem e complementa a análise dos desafios envolvidos em cada narrativa. O filme pode ser comparado a um estudo de caso cuja história apresenta um fio condutor que perpassa diferentes momentos e caminha para um desfecho. A narrativa permite aproximar os estudantes de realidades e conflitos tradicionalmente limitados pela abstração do raciocínio ético (GUILHEM; DINIZ; ZICKER, 2007, p. 85).

Sendo assim, consideramos os filmes uma poderosa ferramenta paradidática, mesmo que não se utilize diretamente na sala de aula, mas que sirva de indicação para os alunos em formação. Não é raro os teóricos da comunicação de massa afirmarem o quanto os telespectadores aprendem com os filmes.

As produções cinematográficas escolhidas para este trabalho foram produzidas nos seguintes países: Brasil (2000), Estados Unidos (2004), França (1952; 2006) e Irã (1998). Quanto ao gênero, as produções se enquadram em documentários e dramas. A seguir apresentamos a sinopse das produções cinematográficas escolhidas: "Invenção de Infância", "Por entre os Muros da Prisão", "Nascidos em bordéis", "Filhos do Paraíso" e "Brinquedo Proibido".

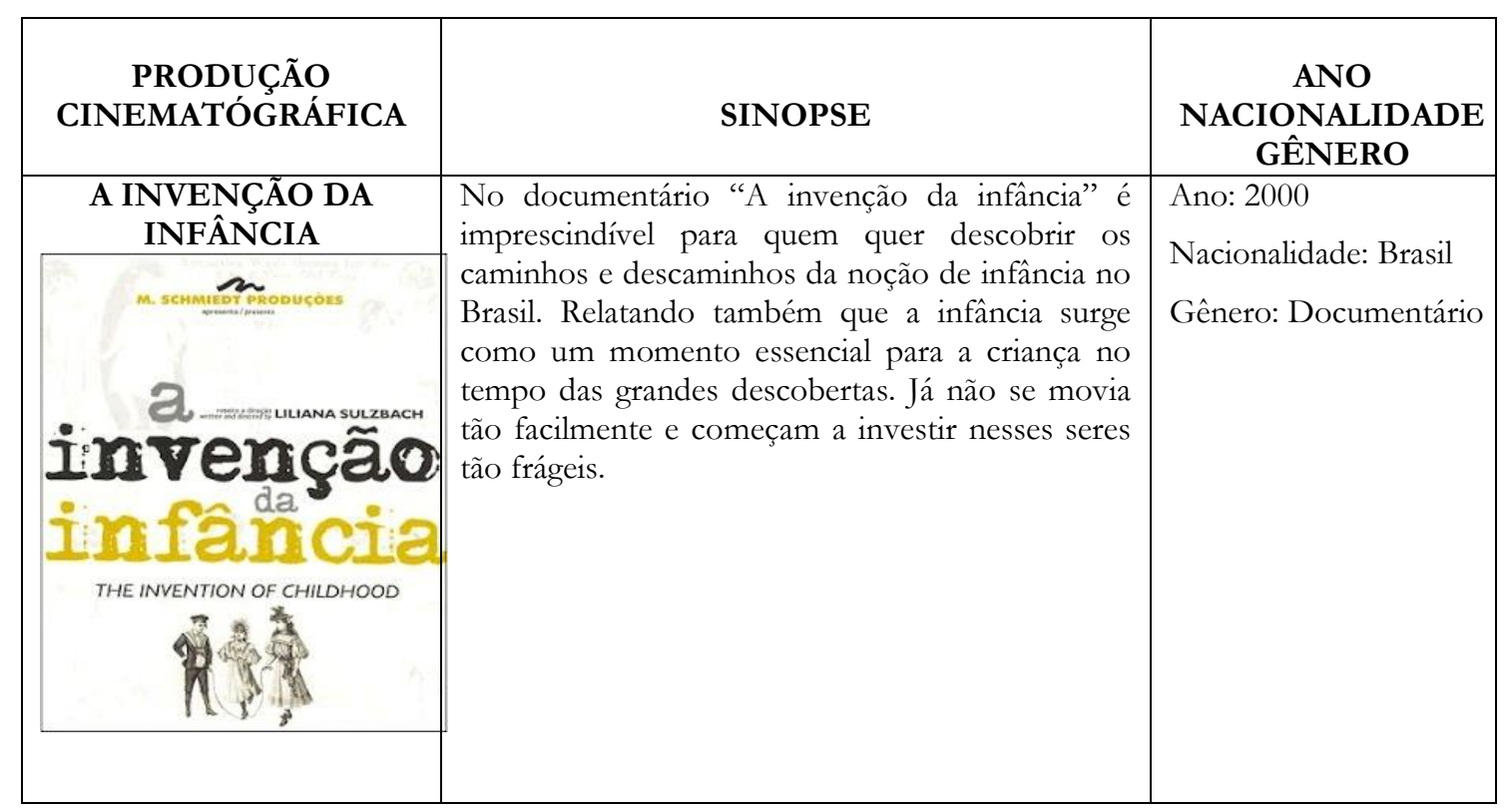


Dossiê: Diálogos interdisciplinares em Psicologia da Educação

| O cinema como fonte investigativa para compreensão da infância: o uso de recursos audiovisuais no ensino de psicologia|

\section{| Laura Maria Silva Araújo Alves |}

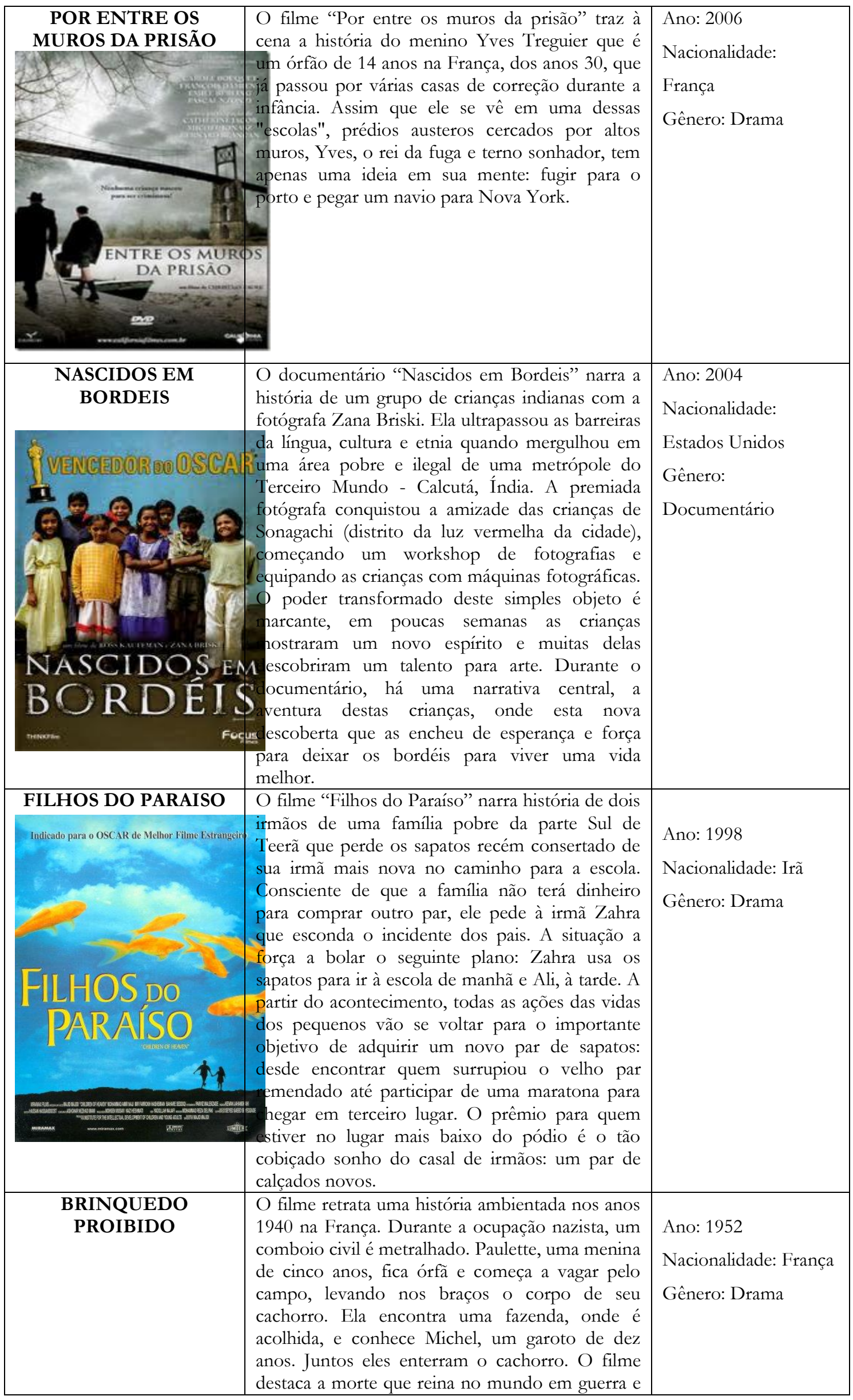


| Laura Maria Silva Araújo Alves |

\begin{tabular}{|l|l|}
\hline BRINQUEDO & que consequentemente reina também no \\
PROIBIDO & mundinho imaginário das duas crianças. As \\
crianças se refugiaram, um mundo no qual vivem \\
uma terna e pura história de amor. Neste \\
universo fechado, eles entregam-se a jogos pueris, \\
também mórbidos. Eles brincam com a morte. \\
Juntos decidem criar um cemitério de animais e \\
roubar algumas cruzes, sem a noção de sacrilégio.
\end{tabular}

\section{A INFÂNCIA NO CINEMA E O ENSINO DA PSICOLOGIA DA APRENDIZAGEM E DESENVOLVIMENTO}

\section{A Invenção da Infância}

No documentário “A Invenção da Infância”, produzido no Brasil em 2000, é interessante para quem quer descobrir e entender a infância no Brasil. O documentário relata, a partir das "vozes" das crianças, que a infância surge como um momento essencial para a criança no tempo das grandes descobertas. Para as crianças inventa-se a infância quando se decide deixá-las brincar, irem à escola e "ser criança".

No decorrer do documentário é possível destacar dois universos de infância socialmente instituídos: a infância da criança pobre e a infância da criança abastada. As crianças pobres do Nordeste brasileiro são vistas como meio de ajuda a família. Mães relatam a perda de muitos filhos devido à situação de pobreza e abandono do poder público. Elas reclamam da perda dos filhos por não poderem ajudar no sustento da família. Desse modo, as crianças são vistas como força de trabalho para seus pais. O documentário destaca a realidade de crianças que vivem no sertão do Nordeste e que pela vida dura que levam, elas não têm o tempo de estudar, de brincar, enfim, não têm infância. Já as crianças das classes abastadas, embora com toda assistência econômica de acesso aos bens culturais. Elas têm muitas atividades cotidianas que as sobrecarregam deixando de lado o tempo de brincar. Diante dessa realidade, ambas as crianças são levadas a pensar e agir como adultos e ter responsabilidades ainda muito cedo. Mesmo diante dessa tarefa de serem responsáveis pela família e por si, as crianças mencionam a tristeza por não sobrar tempo para brincar e estudar, independente das diferenças econômicas, sociais e culturais. 
Dossiê: Diálogos interdisciplinares em Psicologia da Educação

| O cinema como fonte investigativa para compreensão da infância: o uso de recursos audiovisuais no ensino de psicologia|

\section{| Laura Maria Silva Araújo Alves |}

O documentário destaca ainda que a competitividade presente na sociedade moderna, sobretudo nos grandes centros urbanos, atinge significativamente as crianças brasileiras de diferentes grupos sociais. O documentário provoca uma reflexão sobre a exploração do trabalho infantil e dos direitos humanos em relação à infância. Além disso, o documentário faz uma crítica à relação entre a criança e os meios de comunicação de massa e as propagandas televisivas que produzem o consumismo exacerbado nos comportamentos das crianças brasileiras.

À luz das principais correntes psicológicas podemos destacar que o documentário "Invenção de Infância" aborda aspectos socioculturais de Vygotsky ao desvendar a infância da criança pobre e da criança abastada e seus elementos sociais e culturais. As infâncias são perpassadas por práticas culturais que nos fazem entender, como fala Vygotsky, que a criança internaliza conhecimentos da sua realidade e a cultura é o elemento formador (BOCK; GONÇALVES; FURTADO, 2001). Apesar de existir uma legislação brasileira que defini o que é ser criança e também seus direitos reservados à infância, principalmente a partir de políticas públicas que reconhecem à infância, nem sempre ser criança é ter direito a viver uma infância saudável. Há ainda historicamente instituído no filme uma prática de exploração do trabalho infantil e das rotinas das crianças que são cercadas de uma prática do mundo adulto. Nas narrativas das crianças sobre suas infâncias verificarmos que, independente da situação socioeconômica delas, as infâncias são perpassadas por elementos psicológicos que as colocam numa condição de que na contemporânea elas não têm infância.

O documentário traz ainda uma crítica à forma como a criança interage com as novas tecnologias e a modelação de comportamentos que, incentivados pela mídia e propagandas, fazem da criança um sujeito consumista. As modelações de comportamentos sociais são explicadas à luz da teoria skinneriana ${ }^{7}$. As contingências reforçadoras que os adultos estabelecem com as crianças apresentadas no documentário evidenciam o quanto nossas crianças são produtos do seu meio controlador e manipulador (MOREIRA, 1999). Enfim, o documentário nos mostra que, de um lado, as infâncias são carregadas de uma rede de significados que estão ancorados em elementos culturais e sociais que vão determinar a internalização da criança sobre sua infância (REGO, 1988); e de outro lado, que o mundo moderno inventou uma infância carregada de mazelas sociais e psicológicas.

\footnotetext{
7 Skinner é considerado o principal representante da teoria comportamental. Os princípios do comportamentismo de Skinner influenciaram muitos estudos sobre o comportamento humano e as práticas educativas ancoradas em estratégias de reforço e punição para moldar comportamentos adequados.
} 
Dossiê: Diálogos interdisciplinares em Psicologia da Educação

| O cinema como fonte investigativa para compreensão da infância: o uso de recursos audiovisuais no ensino de psicologia|

\section{| Laura Maria Silva Araújo Alves |}

\section{Por entre os muros da prisão}

O filme "Por entre os muros da prisão" retrata a realidade e o cotidiano dos internatos na França dos anos 30 que era carregado de procedimentos pedagógicos rígidos e disciplinares ${ }^{8}$. O personagem principal é Yves Treguier, um órfão de 14 anos que passou por várias casas de correção durante a infância. Assim que ele se vê diante de um sistema escolar como uma prisão, Yves tem apenas uma ideia em sua mente: fugir para o porto e pegar um navio para Nova York. Porém, ele é capturado e entregue aos rígidos procedimentos de disciplina e é obrigado a permanecer naquele ambiente aversivo para ele.

O grupo de alunos do internato, composto por negros africanos, latino-americanos, asiáticos e franceses, apresentam seus anseios, medos, incertezas próprias dessa fase da vida. O professor disciplinador François Marin tem como meta fazer com que os alunos, além de aprenderem o idioma francês, comportem-se como uma turma homogênea, tarefa muito difícil em razão da multiplicidade comportamental da classe, pela formação cultural, econômica e, sobretudo racial.

O filme destaca aspectos de controle e disciplinamento sofridos por um grupo de alunos em uma escola com práticas rígidas que ocasionavam a manipulação de mentes e corpos. O menino Yves, personagem principal, sofre com o sistema de controle do diretor da escola que utiliza estratégias extremamente punitivas para controlar a rebeldia dos alunos. No decorrer do filme, os alunos se rebelam contra as atitudes autoritárias do diretor. É possível destacar ao longo do filme a aversão que os alunos têm do sistema escolar da época, pois há normas e regras disciplinares que causam um grande conflito do diretor com os alunos. Além disso, dentro dos conteúdos estudados sobre a concepção de aprendizagem de Skinner verificamos processos de punição, fuga e esquiva por parte dos alunos 9 .

A prática dos castigos corporais na escola com forma de disciplinamento de comportamentos é apresentada no filme como educação. Havia uma prática recorrente para moldar meninos malcriados e indisciplinados que precisavam ser corrigidos nos seus comportamentos. O sistema de controle e punição estabelecidos pela escola, na França dos

\footnotetext{
${ }^{8}$ Nos séculos XIX e XX, na Europa, houve a criação de institutos orfanatos e internatos para abrigar crianças órfãs, abandonadas e envolvidas com a criminalidade. Estas instituições eram modelos de uma educação disciplinar, rígida e autoritária. O filme "Por entre os muros da prisão" traz à baila a forma cruel e severa com a qual os professores e diretores tratavam as crianças. Castigos corporais eram frequentes, o que gerava nas crianças uma compreensão da escola como uma prisão.

9 No processo de aprendizagem, Skinner condena o uso da punição que tem como efeito colateral levar o aprendiz a associar certas atividades a contingências aversivas. Ele defende o uso de contingências reforçadoras para motivar o aprendiz no sentido de mantê-lo ativo, respondendo e participando da aprendizagem.
} 
Dossiê: Diálogos interdisciplinares em Psicologia da Educação

| O cinema como fonte investigativa para compreensão da infância: o uso de recursos audiovisuais no ensino de psicologia|

| Laura Maria Silva Araújo Alves |

anos 30, nos remete a uma educação extremamente controladora, autoritária, arcaica e conservadora, conforme nos apresenta Skinner sobre a escola como agência controladora. As situações vividas pelo protagonista do filme nos levam aos princípios de que, por longo tempo, as escolas, internatos e institutos educativos na Europa estabeleceram uma prática comportamental de disciplinamento e de punição das crianças. O filme retrará uma escola sem afetividade e motivação para aprendizagem, pois o método tradicional é o que orienta as práticas educativas da escola. Sendo assim, os alunos passam a desenvolver uma aversão pelo espaço escolar em razão das práticas disciplinares rigorosas e extremamente violentas. Enfim, a escola em razão de sua pedagogia disciplinadora e punitiva passa a ser internalizada pelos alunos como uma prisão. Contudo, apesar de toda essa percepção negativa que os alunos têm da escola, há uma relação afetiva que se estabelece entre eles.

\section{Nascidos em Bordeis}

"Nascidos em Bordeis" retrata a vida de um grupo de crianças de um bairro periférico da Zona da Luz Vermelha de Calcutá, Índia. O documentário narra a situação enfrentada pela fotografa Zana Briski, que a priori se encontrava neste local (área pobre e ilegal de uma metrópole do Terceiro Mundo) fotografando as prostitutas e as suas condições de trabalho para fazer um documentário. Ela escolheu como foco as mulheres que tem por herança, após gerações a "profissão" de prostitutas. Para adentrar no mundo das mulheres do distrito da Luz Vermelha, a fotógrafa encontra resistência e vê seu trabalho ameaçado. Para dar continuidade ao seu objetivo, Zana Briski conquista a amizade das crianças desenvolve um workshop de fotografias com as elas que passam a fotografar o cotidiano de suas famílias e do distrito da Luz Vermelha. Como fotógrafa, Zana Briski engajara-se politicamente no uso da arte para denunciar o abandono das crianças pelo poder público do país. Como cenário temos as crianças vivendo uma infância em um contexto de prostituição, tráfico de drogas e bebidas ilícitas, violência, sujeira e pobreza. A fotógrafa consegue com que as crianças (Gour, Shanti, Kochi, Avijit, Puja, Manik, Binod, Tapasi, Madan) por meio das lentes das câmeras mostrem as condições inadequadas que vivem as crianças do distrito da Luz Vermelha. Por meio do envolvimento afetivo com as crianças, Zana Briski consegue o reconhecimento social delas. Seu principal objetivo foi à criação de um ambiente em que cada criança aprendesse e descobrisse sua própria criatividade e autoestima. 
Dossiê: Diálogos interdisciplinares em Psicologia da Educação

| O cinema como fonte investigativa para compreensão da infância: o uso de recursos audiovisuais no ensino de psicologia|

| Laura Maria Silva Araújo Alves |

Os fatos ocorridos no documentário nos fazem perceber que a realidade dessas crianças é gerenciada por práticas culturais e sociais que são disseminados por uma sociedade que ignora os diretos das crianças pobres que vivem no Distrito da Luz Vermelha. No mais, o poder público não reconhece os diretos dessas crianças à escola e à saúde. Ancorando na abordagem sociohistórica de Vygotsky (1980; 1989; 1998) é possível identificar a rede de significados que constituem a infância das crianças, ou seja, sua rede de relações sociais, culturais e afetivas. A visão sociohistórica ${ }^{10}$ de Vygotsky faz entender que esses sujeitos estão imersos na rede de inter-relações familiares e não familiares e que o afastamento da realidade é indubitavelmente uma situação difícil para as crianças daquela comunidade (MOLL, 1996).

Parafraseando Vygotsky, as crianças protagonistas desse documentário são sujeitos que se inserem em um universo sociocultural e que suas consciências são constituídas pelo mundo cultural (OLIVEIRA, 1993). No mais, o documentário dá destaque ao protagonismo das crianças quando elas conseguem desvelar para a sociedade o descaso e o total abandono de suas famílias. As narrativas das crianças são arquitetadas em uma concepção tão negativa da sua realidade em razão de uma rede de relações em que as drogas, o trabalho infantil, a violência doméstica e a prostituição estão presentes no cotidiano delas. O documentário traz à tona elementos ideologicamente construídos sobre as crianças do distrito da Luz Vermelha que demonstram como a infância em países emergentes ainda não é reconhecida de fato e de direito. No mais, o filme aborda que historicamente a infância é marcada por elementos que podem causar comprometimentos nesta fase do desenvolvimento humano.

\section{Filhos do Paraíso}

O filme "Filhos do Paraíso", lançado no Irã, em 1998, conta a história de Ali, um menino de nove anos proveniente de uma família humilde e que vive com seus pais e sua irmã Zahra. É a história de uma família pobre da parte Sul de Teerã. O filme narra o drama do menino Ali que perde os sapatos recém-consertados de sua irmã Zahra no caminho

\footnotetext{
10 A teoria psicológica sociohistórica de Vygotsky (1998) valoriza principalmente a mediação simbólica e se preocupa com as capacidades psíquicas a serem desenvolvidas na inter-relação do sujeito com as demais pessoas. Outro ponto importante é o papel da linguagem na constituição do sujeito. Para Vygotsky, desde o nascimento, a criança está em constante interação com os adultos, que procuram incorporar nessa interação conhecimentos da cultura, atribuindo significado às condutas e aos objetos culturais que se formaram ao logo da história do homem. Assim, a criança internaliza conhecimentos por meio das interações sociais e culturais. Conforme o pensamento vygotskiano, o desenvolvimento e a aprendizagem do sujeito humano se dão a partir das constantes interações com o meio social em que este vive.
} 
Dossiê: Diálogos interdisciplinares em Psicologia da Educação

| O cinema como fonte investigativa para compreensão da infância: o uso de recursos audiovisuais no ensino de psicologia|

\section{| Laura Maria Silva Araújo Alves |}

para a escola. Consciente de que a família não terá dinheiro para comprar outro par, ele pede à irmã Zahra que esconda o incidente dos pais em razão das condições financeiras da família. A situação força os irmãos a arquitetar um plano: Zahra usa os sapatos para ir à escola de manhã e Ali, à tarde. Parte do filme narra o drama vivido pelos irmãos diante do referido plano. Há inúmeros acontecimentos diversos que produzem comportamentos de medos e constrangimentos na escola. A partir dos acontecimentos negativos, todas as ações das vidas das duas crianças vão se voltar para o importante objetivo de adquirir um novo par de sapatos: desde encontrar quem surrupiou o velho par remendado até participar de uma maratona para chegar em terceiro lugar. O prêmio para quem estiver no lugar mais baixo do pódio é o tão cobiçado sonho do casal de irmãos: um par de calçados novos.

No decorrer das aventuras do filme, os dois irmãos mostram os dois lados do Irã quando Ali vai, com seu pai, trabalhar de jardineiro nas mansões do outro lado da cidade. Mesmo ganhando o primeiro lugar na maratona, Ali fica triste, pois o primeiro lugar não tinha como prêmio o tênis que ele precisava para sua irmã. Durante a premiação as pessoas não conseguem entender a tristeza dos irmãos.

O filme retrata aspectos do universo infantil como, por exemplo, os valores morais e sociais que permeiam os comportamentos dos dois irmãos. A história mostra um lar onde, embora a pobreza e a doença da mãe dos irmãos, existe o amor e o apoio mútuos, amizade e respeito; muita honestidade, apesar das grandes dificuldades e carências; solidariedade entre vizinhos; a disciplina na escola; os costumes familiares, sociais e religiosos iranianos. $\mathrm{Na}$ trama que envolve as duas crianças podemos observar, de acordo com Piaget e Vygotsky, que temas como cumplicidade, amizade e imaginário fazem parte da realidade não somente dos irmãos Ali e Zahar, mas são elementos presentes no contexto do universo infantil das crianças apresentadas no filme.

A relação de cumplicidade e amizade entre os dois irmãos favorece a compreensão que Piaget ${ }^{11}$ faz da criança ao apontar elementos relevantes no universo infantil como o simbolismo, egocentrismo social e valores morais (GOURLAT, 1983). Segundo Piaget, toda moral consiste numa internalização de sistema de regra (MOREIRA, 1999). No mais, entre o repertório comportamental dos dois irmãos podemos verificar um imaginário repleto de afetividade e cumplicidade. Embora com todas as dificuldades econômicas de seus pais, as crianças protagonistas revelam a capacidade imaginária de superação das

${ }^{11}$ Para Piaget, o mecanismo de interação da criança com o ambiente é construído por um movimento em espiral ascendente que se dá em dois polos: assimilação e acomodação. A assimilação é a incorporação dos dados da realidade exterior, do ambiente, aos esquemas de ação/cognitiva já construídos pela criança. A acomodação, por sua vez, é a mudança que se realiza nestes esquemas de ação. Portanto, para Piaget não há assimilação sem acomodação e vice-versa. 
Dossiê: Diálogos interdisciplinares em Psicologia da Educação

| O cinema como fonte investigativa para compreensão da infância: o uso de recursos audiovisuais no ensino de psicologia|

\section{| Laura Maria Silva Araújo Alves |}

dificuldades (OLIVEIRA, 1993). De acordo com Wallon ${ }^{12}$, as crianças desenvolvem nas suas relações sociais a afetividade, ou seja, na primeira etapa de desenvolvimento, que é correspondente ao primeiro ano de vida do ser humano, o que predomina é a relação com o meio, a afetividade com outros indivíduos.

\section{Brinquedo Proibido}

"Brinquedo Proibido", produzido em 1952, é um dos maiores clássicos do cinema francês do pós-guerra sobre a infância. O filme retrata a criança diante das mazelas da guerra. Em junho de 1940, durante a ocupação nazista na França, um comboio civil é metralhado e Paulette, uma menina de cinco anos, fica órfã e começa a vagar pelo campo, levando nos braços o corpo de seu cachorro. Após uma longa caminhada sem destino, Paulette encontra uma fazenda, onde é acolhida, e conhece Michel, um garoto de 11 anos. Juntos eles enterram em um moinho abandonado o cachorro e criam neste lugar um cemitério para os animais mortos da região. Ambos decidem criar um cemitério de animais e roubar algumas cruzes, sem a noção de sacrilégio. Para desespero dos adultos há o desaparecimento de todos os crucifixos locais, inclusive, o da igreja do lugarejo, para surpresa do padre e da comunidade. Todos ficam intrigados com o desaparecimento desse objeto sagrado.

A criação do cemitério de animais é indubitavelmente uma forma imaginária que as crianças encontram de fugir da realidade triste e cruel de uma guerra. Ao refugiar-se nesta fazenda, a menina Paulette encontra no amiguinho Michel um meio de amenizar o sofrimento desencadeado pela perda de sua família. Ao encontrar afeto nesta relação, ela constrói junto com ele um mundo imaginário onde a perda familiar, a pobreza e o sofrimento da guerra gerou nas crianças à época. Perturbados pela loucura dos adultos em razão dos resquícios da guerra, eles vão estabelecer um laço de amizade singela e pura, mas igualmente fragilizada pela presença da morte e da incompreensão e desajuste psíquico dos adultos em lidar com a situação. A relação que acontece com a menina Paullette e o menino Michel é simbolicamente muito significativa para ambos se desvencilharem das sequelas que a guerra deixou nas mentalidades dos adultos. A capacidade imaginária que se desenvolve entre as crianças é uma forma de se equilibrar diante de um grande conflito que

12 Para Wallon, a interação afetiva cognitiva motora também está entrelaçada na interação com o meio, uma vez que a criança se desloca e reage de certa forma aos estímulos que recebe tanto do ambiente social e cultural. A partir da concepção de Wallon podemos entender que a criança está imersa não somente em práticas culturais e sociais, mas, principalmente, em uma rede de relações afetivas. 
Dossiê: Diálogos interdisciplinares em Psicologia da Educação

| O cinema como fonte investigativa para compreensão da infância: o uso de recursos audiovisuais no ensino de psicologia|

| Laura Maria Silva Araújo Alves |

é uma guerra e suas consequências nas mentes das pessoas (RICHMOND, 1981). A convivência entre as crianças (Michel e Paulette) traduz de forma surpreendente como que a maioria das crianças supera temas como a morte e o luto familiar.

As crianças, como dizem Piaget e Vygotsky, criam um mundo imaginário para superar as mazelas da vida de foram natural (VYGOTSKY, 1989; 1980). Ambas as crianças demonstraram seus sentimentos pela morte do cachorro, criando a brincadeira de colecionar insetos e animais num cemitério. Outro aspecto apontado no filme é a relação afetiva entre as duas crianças protagonistas da história diante do segredo que compartilham. Temas como delicadeza, cumplicidade e amizade são abordados no filme do início ao fim. A morte, tema extremamente doloroso para os adultos diante a tragédia da guerra, reina no mundinho imaginário das duas crianças que se refugiam num fantasia imaginário no qual vivem uma terna e pura história de amor, amizade e companheirismo. Neste universo fechado, as duas crianças se entregam naturalmente aos temas mórbidos com a morte, abandono e desequilíbrio dos adultos e velhos diante da guerra. Eles brincam com a morte como meio de superação das adversidades enfrentadas pelas grandes perdas de suas identidades pessoais, sociais e culturais. O filme nos faz refletir sobre o abandono, a orfandade e as mazelas psíquicas que a guerra produziu nas crianças.

\section{CONSIDERAÇÕES FINAIS}

Associar o uso de filmes a conteúdos teóricos da Psicologia que abordam a infância foi considerado uma experiência enriquecedora para os alunos de graduação em Letras, pois contribuiu para a instrumentalização dos conteúdos das teorias de aprendizagem e desenvolvimento, para motivar e fixar o aprendizado. Um ganho adicional foi a aproximação com temas pouco explorados no ensino de graduação em Licenciatura em Letras no qual muitos acadêmicos não têm um referencial de vivência com a criança e o universo infantil.

O uso de filmes ofereceu vantagens pelo fato de ser um meio motivador para os alunos, por mobilizar o interesse deles e, ainda, em razão dos filmes serem fontes de experiências emocionais e cognitivas que permitem ampliar a visão de mundo e aperfeiçoar as competências, habilidades e atitudes dos acadêmicos sobre a infância.

A utilização de filmes no contexto do ensino de Psicologia é importante ferramenta de motivação para despertar o interesse sobre determinado tema ou assunto e, ainda, para fomentar motivações para a leitura de textos e posteriormente debates em sala de aula. 
Dossiê: Diálogos interdisciplinares em Psicologia da Educação

| O cinema como fonte investigativa para compreensão da infância: o uso de recursos audiovisuais no ensino de psicologia|

| Laura Maria Silva Araújo Alves |

Finalmente, observa-se que a introdução de filmes representa mais uma oportunidade para rever e sofisticar a abordagem pedagógica e os conteúdos de psicologia em sala de aula. No entanto, por constituírem produtos complexos, com dimensões culturais, artísticas e comerciais, os filmes não são um recurso de manipulação simples. Para ultrapassar estas barreiras, sugere-se: (1) a elaboração de fichas técnicas dos filmes; (2) a leitura de artigos científicos relacionados ao tema abordados; (3) aulas expositivas para estimular os debates em sala de aula e redimensionamento da carga horária da disciplina.

Um dos aspectos de limitação para o uso do filme em sala de aula é a sua duração, em torno de aproximadamente uma hora e meia. Os alunos devem dispor deste tempo corrido para assistir ao filme, mas é pertinente experimentar ver o filme no contexto extraclasse, e debatê-lo em conjunto. A possibilidade de uso de filmes e documentários como estratégia didática pedagógica nas disciplinas de Psicologia, para os alunos de graduação em Letras, foi relevante para a compreensão da infância e seus elementos construtivos.

É necessário que haja um investimento nas universidades em ambientes que favoreça a aplicação de recursos audiovisuais nas aulas de Psicologia dado o valor estruturante da tal prática para a formação de professores e para motivação dos alunos. No entanto, ações de investimento são tarefas que extrapolam o fazer diário de um professor. Há de se pensar uma estratégia de obtenção de recursos para compra de filmes e de investimentos em espaços para projeção de filmes e de acervo para essa prática didática no ensino de Psicologia nas universidades.

Em geral, os alunos de graduação recorrentemente relatam em sala de aula a dicotomia entre teoria e prática na sua formação. No caso da disciplina de Psicologia (Aprendizagem e Desenvolvimento) essa dicotomia é superada com atividades de observação, pesquisas de campo e estudos de caso por meio do cinema, pois somente através da imersão dos alunos no mundo real da escola e da infância é que se estará permitindo efetivamente ato de conhecimento sobre o universo infantil. As práticas pedagógicas que não problematizam o real certamente não formaram profissionais reflexivos, criativos, críticos, autônomos e investigador constante de sua prática. A articulação teoria a prática no âmbito da Psicologia deve ser uma constante. Dentre as propostas de intermediação entre teoria e prática está a utilização de filmes.

\section{REFERÊNCIAS}


| Laura Maria Silva Araújo Alves |

AZZI, Roberta Gurgel; BATISTA, Sylvia Helena Sousa da; SADALLA, Ana Maria Falcão de Aragão (Org.). Formação de Professores: discutindo e ensino de psicologia. Campinas: São Paulo: Editora Alínea, 2000. p. 105.

BOCK, Ana Maria; GONÇALVES, M. Graça; FURTADO, Odair (Org.). Psicologia sócio-histórica: uma perspectiva crítica em psicologia. São Paulo: Cortez, 2001.

GAT'TI, Bernadete. A estrutura e dinâmica das Licenciaturas: problemas antigos, alternativas e o papel da psicologia da educação. Psicologia da Educação, São Paulo, n. 01, p. 21-33, nov. 1995.

Formação de professores e carreira: problemas e movimentos de renovação. Campinas, SP: Autores Associados, 1997.

Os professores e suas identidades: o desvelamento de heterogeneidade. Cadernos de Pesquisa, São Paulo, n. 98, p. 85-86, ago. 1996.

GOULART, Iris Barbosa. Piaget: experiências básicas para utilização pelo professor. 5. ed. Petrópolis: Vozes, 1983.

GUILHEM, D.; DINIZ, Debora; ZICKER. Pelas lentes do cinema: bioética e ética em pesquisa. Brasília: Letras Livres; EdUnB, 2007, p.85.

LAROCCA, Priscila. O ensino de Psicologia no espaço das licenciaturas. Educação Temática Digital, Campinas, v. 8, n. 2, p. 295-307, jun. 2007.

Ensino de psicologia e seus fins na formação de professores: uma discussão mais que necessária. Temas em Psicologia, Ribeirão Preto, v. 15, n. 1, p. 57-68, jun. 2007.

O saber psicológico e a docência: reflexões sobre o ensino de psicologia na educação. Psicologia: Ciência e Profissão, Brasília, v. 20, n. 2, p. 60-65, jun. 2000.

MERCURI, E.; SOARES, C.; BATISTA, S. H. Egressos dos cursos de licenciatura da UNICAMP: subsídios para avaliação dos cursos. REUNIÃO ANUAL DA ANPED, 1999, Caxambu. Anais... Caxambu: ANPED, 1999.

MOLL, L. C. Vygotsky e a educação: implicações pedagógicas da psicologia sóciohistórica. Porto Alegre: Artes Médicas, 1996.

MOREIRA, Marco Antônio. Teorias de aprendizagem. Porto Alegre: E.P.U, 1999.

NÓVOA, J.; FRESSATO, S. B.; FEIGELSON, K. (Org.). Cinematógrafo: um olhar sobre a história. Salvador: EDUFBA; São Paulo: Editora da UNESP, 2009. p. 169-175.

OLIVEIRA, D. T. L. A formação do professor de psicologia: estudo de uma licenciatura em psicologia. 1993. Dissertação (Mestrado em Educação) - Faculdade de Educação, Universidade Estadual de Campinas, Campinas, 1993.

OLIVEIRA, Marta Kohl de. Vygotsky: aprendizagem e desenvolvimento. São Paulo: Ed. Scipione, 1993. 
| O cinema como fonte investigativa para compreensão da infância: o uso de recursos audiovisuais no ensino de psicologia|

\section{| Laura Maria Silva Araújo Alves |}

REGO, T. C. Vygotsky: uma perspectiva histórico-cultural da educação. 13. ed. São Paulo: Editora Vozes, 2002.

RICHMOND, Peter Graham. Piaget: teoria e prática. 3. ed. São Paulo: IBRASA, 1981.

VYGOTSKY, L. S.; LURIA, Alexander R.; LEONTIEV, Alexis N. Linguagem, desenvolvimento e aprendizagem. São Paulo: Ícone, 1980.

VYGOTSKY, L. S. A formação social da mente. 3. ed. São Paulo: Martins Fontes, 1989.

Pensamento e linguagem. 2. ed. São Paulo: Martins Fontes, 1998.

\section{FILMES}

INVENÇÃO de Infância, A. Direção: Liliana Sulzbach. Brasil, 2000. 26 min. Son, Color, Formato: $16 \mathrm{~mm}$.

POR ENTRE os Muros da Prisão. Direção: Christian Faure. França, 2006. 1h35min. Son, Color, Formato: $16 \mathrm{~mm}$.

NASCIDOS em Bordéis. Direção: Zana Brisk; Ross Kauffanan. Estados Unidos, 2004. 1h28min. Son, Color, Formato: 16mm.

FILHOS do Paraíso. Direção: Majid Majid. Irã, 1998. 1h28min. Son, Color, Formato: 16 $\mathrm{mm}$.

BRINQUEDO Proibido. Direção: René Clément. França, 1952. 1h25min. Son, Color, Formato: $16 \mathrm{~mm}$. 